
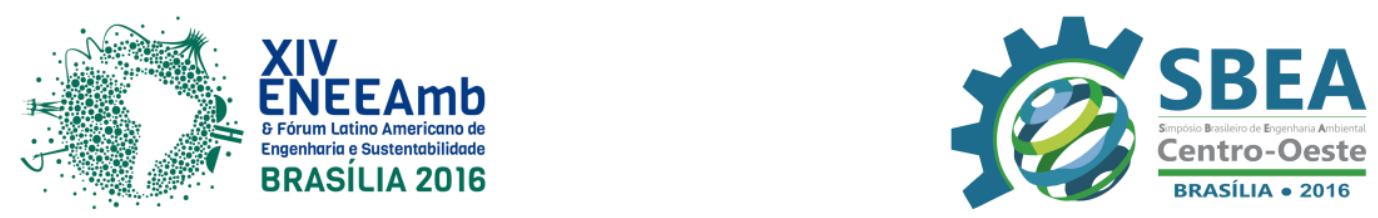

MONITORAMENTO AMBIENTAL

\title{
CARACTERIZAÇÃO DO USO E COBERTURA DO SOLO NO ENTORNO DO CÓRREGO BREJO COMPRIDO, MUNICÍPIO DE PALMAS - TO.
}

\author{
Danillo Silva Nunes - danillosnunes@live.com \\ Graduando em Engenharia Ambiental, Universidade Federal do Tocantins.
}

Eduardo Quirino Pereira - eduquirino@ gmail.com

Professor Assistente do curso de Engenharia Ambiental, Universidade Federal do Tocantins.

\begin{abstract}
Resumo: Este trabalho objetivou o mapeamento do entorno do Córrego Brejo Comprido, município de Palmas - TO, utilizando imagens de alta resolução obtidas pelo programa Google Earth Pro, com a finalidade de caracterizar o atual uso da terra e cobertura vegetal, identificando as fitofisionomias presentes, bem como as classes de uso, debatendo a respeito da aplicabilidade da legislação vigente na preservação do corpo hídrico. Foi-se observada à presença marcante, desde suas nascentes, localizadas na Serra do Lajeado, até sua foz no lago da UHE Lajeado, de áreas antropizadas, com a presença de chácaras, pontos com supressão de vegetação e outros. Entre as classificações de fitofisionomias, a mais presente foi a Mata de Galeria, ocupando aproximadamente 53\% da área de estudo. Concluiu-se que conforme prevê a legislação federal, a maior parte dos pontos em zona rural, estão em conformidade com as áreas de proteção dispostas na Lei Federal $n^{\circ}$ 12.651/2012, entretanto, inclusão do perímetro de área urbana como Unidade de Conservação por Lei Complementar Municipal no 155/2007, acaba por não atender aos pré-requisitos definidos pela mesma.
\end{abstract}

Palavras-chave: Brejo Comprido; Palmas; Uso e Cobertura.

\section{INTRODUÇÃO E OBJETIVOS}

As ações antrópicas têm gerado impactos significativos nas paisagens fitofisionômicas, através do intenso processo de substituição das áreas naturais por variados tipos de uso do solo e fragmentação das áreas com cobertura florestal. Tais práticas podem influenciar a disponibilidade e qualidade dos recursos naturais, além de afetar a biodiversidade em grandes áreas do planeta (COELHO et al, 2014).

O município de Palmas - TO, está localizado na mesorregião Oriental do Tocantins, microrregião de Porto Nacional (IBGE, 1991). A zona urbana do município está estabelecida à margem do lago formado pela Usina Hidroelétrica Luís Eduardo Magalhães UHE Lajeado, e os principais cursos d'água que cortam a área urbana são Córrego Água Fria, 

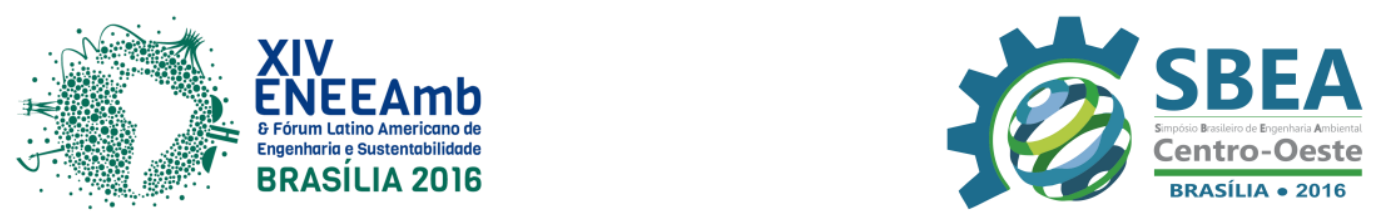

Córrego Sussuapara, Córrego Brejo Comprido, Córrego do Prata, Taquaruçu Grande e Taquari (PALMAS, 2014).

No plano urbanístico do município, podem ser observadas três áreas verdes marcantes que constituem parte de um conjunto de fontes naturais: o córrego Sussuapara, Brejo Comprido e Prata. São áreas privilegiadas e de grande importância à qualidade de vida da população, sendo importante estudos que visem um melhor planejamento sustentável do local (ARRAIS, 2009).

Promulgada em 28 de novembro de 2007, a Lei Complementar $n^{\circ} 155 / 2007$ da cidade de Palmas - TO, dispõe sobre a política urbana do município, e em seu art. 29, inciso III, cria a Unidade de Conservação Brejo Comprido, definindo uma faixa de preservação de $100 \mathrm{~m}$ (cem metros) de cada lado do corpo d'água até o encontro com a cota $212 \mathrm{~m}$ do reservatório da UHE Lajeado (PALMAS, 2007).

O monitoramento sobre uso e cobertura da terra é um dos instrumentos mais importantes no planejamento de políticas públicas que visem barrar o avanço da ocupação antrópica sobre os remanescentes florestais, principalmente aqueles que desempenham influência direta na proteção da qualidade ambiental de corpos hídricos, bem como no acompanhamento da evolução de áreas em regeneração.

Dentre os instrumentos de maior crescimento para trabalhos relacionados ao monitoramento ambiental, o uso de imagens disponibilizadas pelo Google Earth tem destaque por sua facilidade de acesso e possibilidade de grande discriminação de alvos, auxiliando na eliminação de dúvidas de interpretação (IBGE, 2013).

Tendo em vista esse cenário, esse trabalho objetiva caracterizar o atual uso e cobertura da terra, através de imagem fornecida pelo Google Earth Pro, da área entorno ao Córrego Brejo Comprido, município de Palmas - TO, correlacionando as fitofisionomias e formas de utilização do solo com a legislação vigente.

\section{METODOLOGIA}

\subsection{Caracterização da área de estudo}

O córrego Brejo Comprido tem sua bacia hidrográfica delimitada pelas coordenadas UTM 800086 e 787670 de latitude Sul e 8869121 e 8874527 de longitude Oeste, estando situado no município de Palmas - TO, ocupando uma área de $56,4 \mathrm{~km}^{2}$ (SOUZA \& FIGUEROA, 2012).

Antes da formação do lago da UHE Lajeado, o mesmo era afluente do Córrego Água Fria, desaguando atualmente no próprio reservatório. Possui dois terços de sua extensão em zona urbana $\left(46,1 \mathrm{~km}^{2}\right)$, numa área bastante consolidada do perímetro urbano com a 

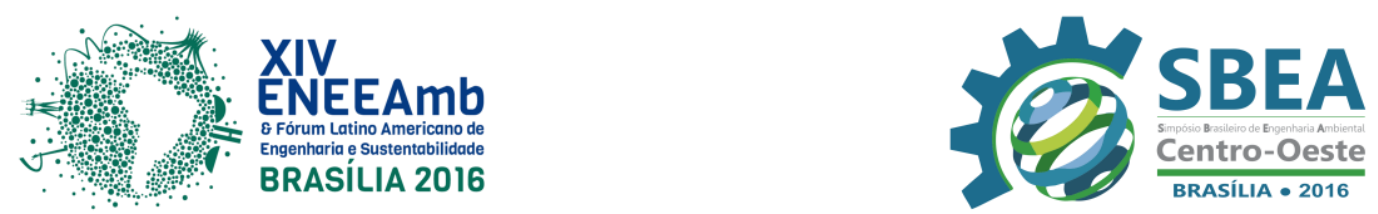

presença do Parque Cesamar, na sua cabeceira (PALMAS, 2014). A microbacia do córrego encontra-se demonstrada na figura 1.

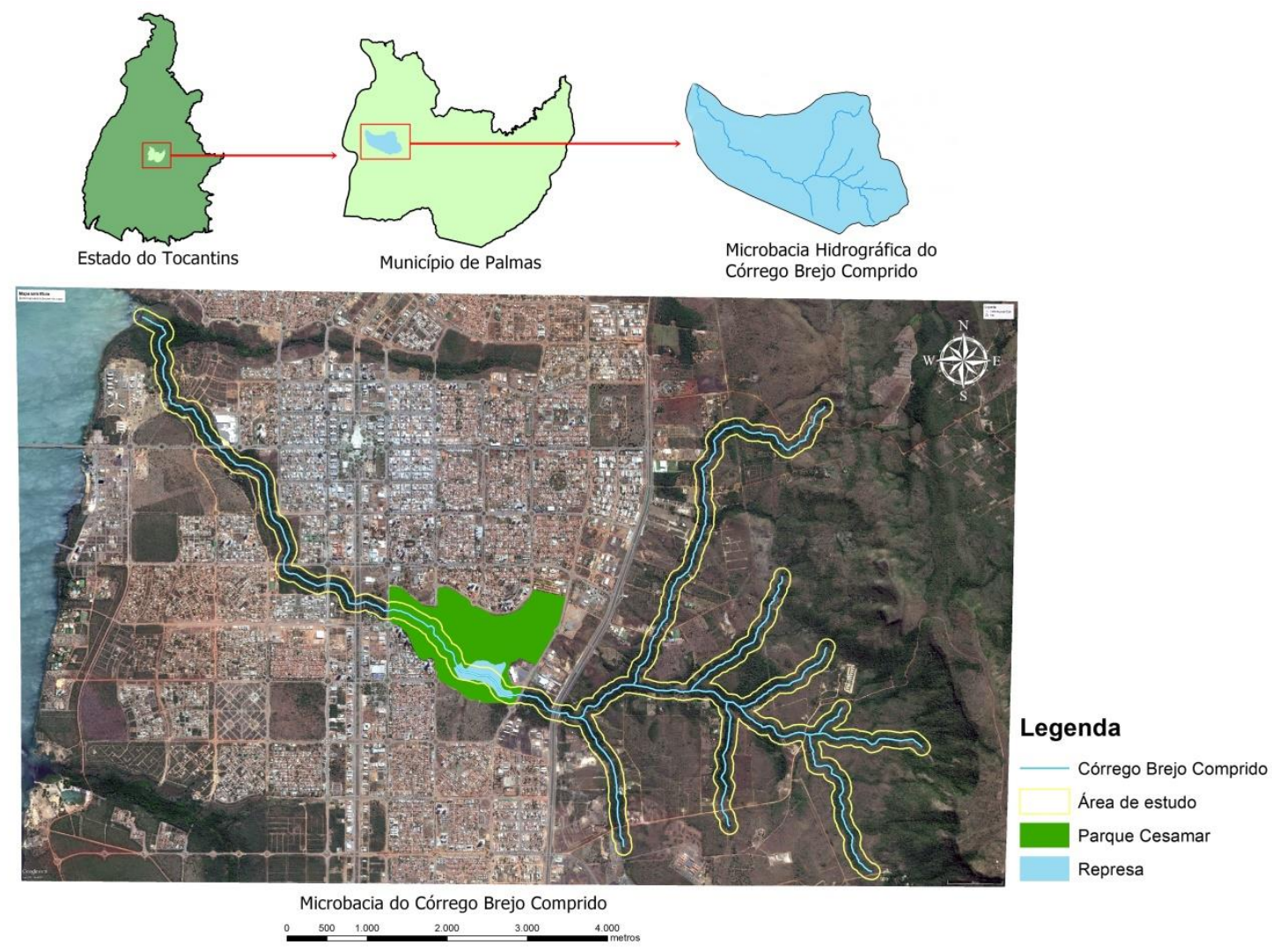

Figura 1 - Localização da microbacia do Córrego Brejo Comprido

A respeito da intervenção antrópica, o córrego Brejo Comprido possui pontos de captação de água para irrigação de parques e jardins, e também locais de descarte de efluentes tratados, não tratados e ainda de resíduos sólidos. Possui em parte do seu curso um lago criado por represamento, cujo volume d'água é de aproximadamente $500.000 \mathrm{~m}^{3}$, compondo o Parque Cesamar, utilizado pela população para práticas esportivas e de recreação (PALMAS, 2014).

\subsection{Método de análise}

Inicialmente, foi-se mapeado utilizando o software Google Earth Pro, toda a hidrografia do Córrego Brejo Comprido, desde as nascentes dos afluentes e canal principal, até a foz. O arquivo gerado foi então exportado para o programa QuantumGIS para vetorização e posterior utilização na plataforma ESRI.

Uma vez exportado para a plataforma ESRI, o arquivo foi editado no programa ArcGIS 10.2.2, onde foi gerado com a função "buffer", uma zona tampão de 100 (cem) metros em torno dos cursos d'agua em estudo. Partindo disso, houve a delimitação das feições 

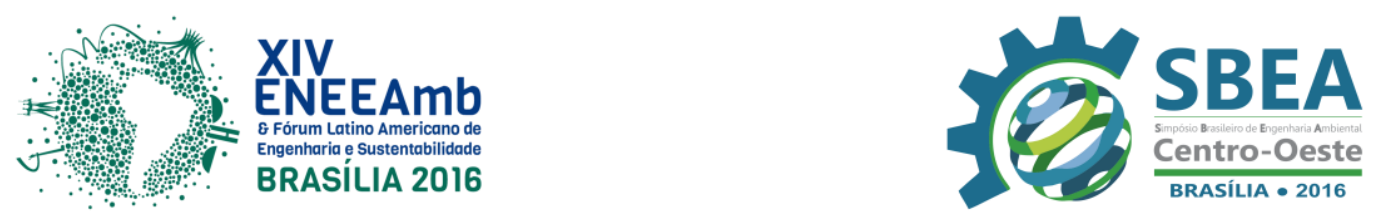

de uso e cobertura do solo com base em imagem de alta resolução abrangente a área de estudo, também obtida pelo programa Google Earth Pro, com altitude do ponto de visão equivalente a 3000 (três mil) metros, posteriormente georreferenciada usando sistema de projeção cartográfica UTM (Universal Transversa de Mercartor), fuso 22S, Datum SIRGAS 2000.

A definição das classes de uso da terra foi feita conforme Manual Técnico de Uso da Terra (IBGE, 2013), com adaptações para melhor aplicabilidade na escala de detalhamento utilizada, sendo a classificação da cobertura vegetal feita com base no trabalho de Ribeiro e Walter (1998), conforme recomendado pelo Manual Técnico da Vegetação Brasileira (IBGE, 2012) para classificação de fitofisionomias do bioma Cerrado. A classificação utilizada no uso e cobertura é demonstrada na tabela 1.

Tabela 1 - Classificação de uso e cobertura vegetal do solo.

\begin{tabular}{|c|c|c|c|}
\hline \multicolumn{4}{|c|}{ USO DA TERRA $^{1}$} \\
\hline \multirow{3}{*}{$\begin{array}{l}\text { Áreas } \\
\text { Antrópicas } \\
\text { Não } \\
\text { Agrícolas }\end{array}$} & \multirow{3}{*}{ Áreas Urbanizadas } & Cidade & Área Edificada \\
\hline & & & Vias de Acesso \\
\hline & & Outras áreas urbanizadas & Chácaras (zona rural) \\
\hline \multirow{2}{*}{$\begin{array}{l}\text { Áreas } \\
\text { Antrópicas } \\
\text { Agrícolas }\end{array}$} & Pastagens & \multicolumn{2}{|c|}{ Pecuária de Animais de grande porte } \\
\hline & $\begin{array}{l}\text { Culturas } \\
\text { Permanentes }\end{array}$ & \multicolumn{2}{|l|}{ Frutíferas Permanentes } \\
\hline Água & Águas Continentais & \multicolumn{2}{|c|}{ Lazer e desporto em corpo d'água continental } \\
\hline \multirow{2}{*}{$\begin{array}{l}\text { Outras } \\
\text { áreas }\end{array}$} & Áreas descobertas & \multicolumn{2}{|c|}{ Uso não identificado em área descoberta } \\
\hline & \multicolumn{3}{|l|}{ Áreas Antropizadas } \\
\hline \multicolumn{4}{|c|}{ COBERTURA VEGETAL ${ }^{2}$} \\
\hline \multirow{3}{*}{$\begin{array}{l}\text { Bioma } \\
\text { Cerrado }\end{array}$} & Formações Florestais & \multicolumn{2}{|l|}{ Mata Ciliar } \\
\hline & \multirow{2}{*}{ Formações Savânicas } & \multirow{2}{*}{ Cerrado Sentido Restrito } & Cerrado Ralo \\
\hline & & & Cerrado Típico \\
\hline
\end{tabular}

Fonte: Adaptado ${ }^{1}$ IBGE (2013); ${ }^{2}$ Ribeiro \& Walter (1998).

Após feita a classificação, foi calculada a área em hectares de cada feição e então elaborada uma tabela contendo os respectivos valores absolutos e percentuais dos usos e fitofisionomias identificados.

\section{RESULTADOS E DISCUSSÕES}

Através da delimitação e quantificação das unidades de uso e fitofisionomias mapeadas, foi elaborada a carta de mapeamento (esc.: 1:25.000), demonstrada na figura 2 e as respectivas áreas, expressas na tabela 2. 


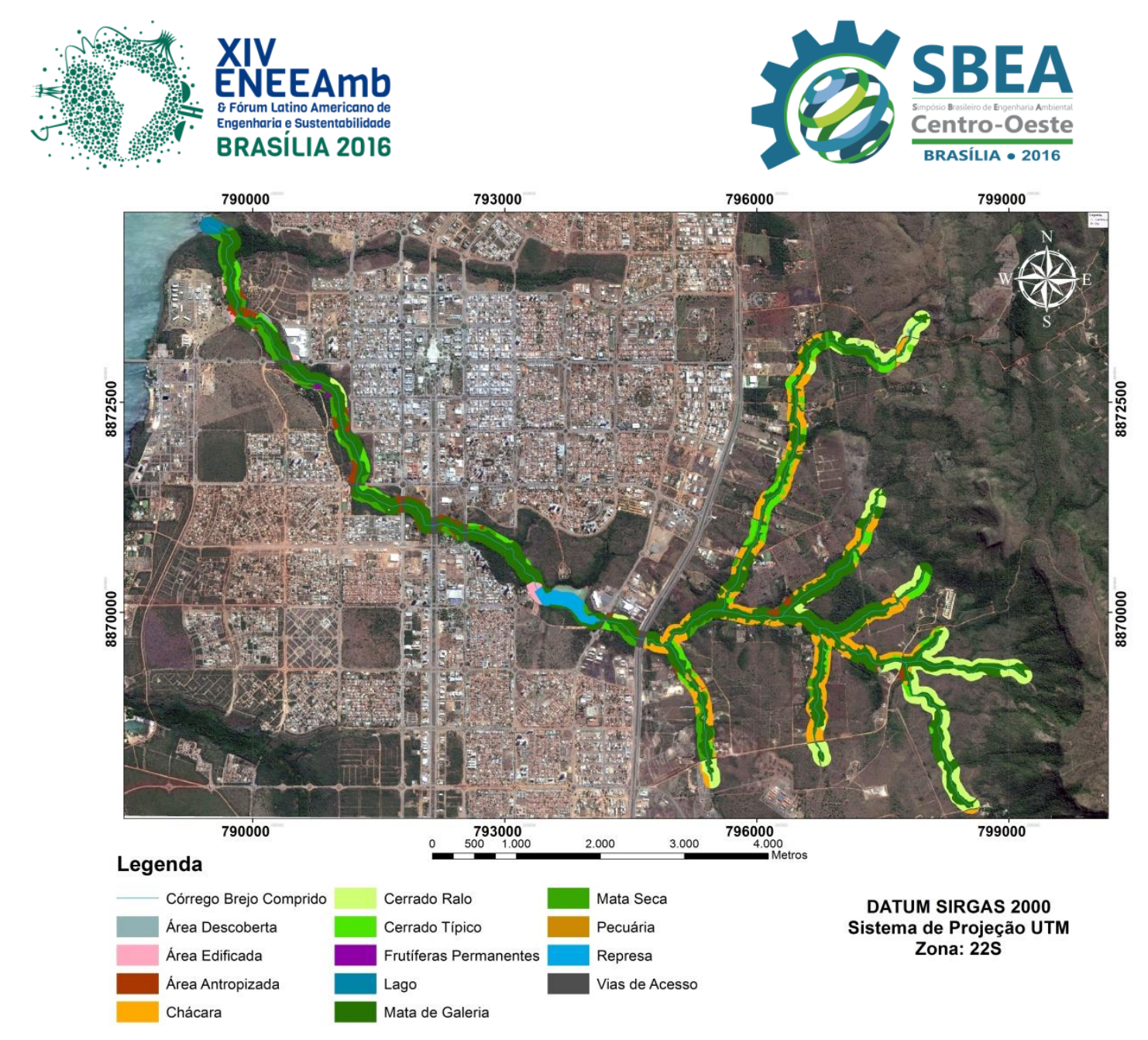

Figura 2 - Carta de uso e cobertura do solo entorno ao Córrego Brejo Comprido.

Tabela 2 - Áreas das classes de uso e cobertura do solo.

\begin{tabular}{|l|c|c|}
\hline \multicolumn{1}{|c|}{ CLASSES } & ÁREA (ha) & \% \\
\hline Áreas Descobertas & 1,83 & 0,33 \\
\hline Área Edificada & 2,02 & 0,36 \\
\hline Área Antropizada & 14,74 & 2,63 \\
\hline Chácaras & 73,01 & 13,02 \\
\hline Cerrado Ralo & 76,79 & 13,70 \\
\hline Cerrado Típico & 36,27 & 6,47 \\
\hline Frutíferas Permanentes & 0,84 & 0,15 \\
\hline Mata de Galeria & 298,74 & 53,28 \\
\hline Mata Seca & 32,37 & 5,77 \\
\hline Pecuária & 0,14 & 0,03 \\
\hline Represamento & 12,44 & 2,22 \\
\hline Vias de Acesso & 11,49 & 2,05 \\
\hline$\Sigma$ & 560,68 & 100,00 \\
\hline
\end{tabular}

No que diz respeito à cobertura vegetal, nota-se que predominantemente no entorno do córrego, encontra-se a fitofisionomia "Mata de galeria", correspondendo a mais da 

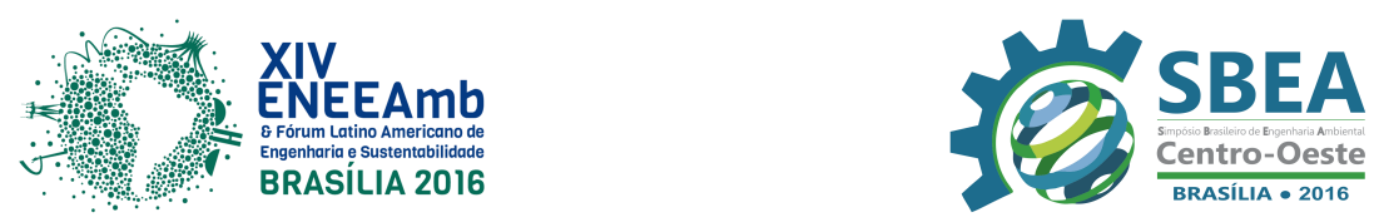

metade da área de estudo (53,28\%), indo desde suas nascentes até a foz, o que já era esperado, tendo em vista a abrangência da análise. Percebe-se ainda, mudanças bruscas na cobertura da maior parte dos pontos, entre as formações florestais para as formações savânicas, característica típica do bioma cerrado. Além disso, não foram identificados representantes da sub-divisão "Cerradão", o que condiz com trabalho elaborado por Guarda (2006), que avaliou a dinâmica do uso da terra em toda a microbacia do córrego.

No alto curso do córrego, zona rural do município, é notória a presença de chácaras e áreas antropizadas isoladas, onde a vegetação suprimida está em estágio de regeneração. Isso serve de alerta para os impactos que podem ocorrer oriundos da possível destinação inadequada de resíduos e efluentes domésticos, além da eventual supressão da vegetação para fins múltiplos do terreno. Dentre as atividades, a pecuária ocupa uma pequena parcela de $0,03 \%$ da área, pouco mais de 0,14 hectare.

No médio curso, adentrando no perímetro urbano do município, observa-se a presença de vegetação disposta de forma uniforme e bem preservada na área que abrange o Parque Cesamar. A lei municipal no 1406/2005, que institui o plano de uso e ocupação do parque, prevê que o mesmo detenha parte de seu território como reserva biológica, assegurando a proteção do manancial hídrico. As áreas antropizadas observadas são contempladas na legislação como "Áreas de Paisagem Cultural", constituindo uma porção do território que já possuía prédios públicos antes da criação do parque.

Seguindo o curso do corpo hídrico, após o término da área do parque, em direção à foz, nota-se o aumento nas áreas antropizadas e edificadas, podendo trazer riscos à permeabilidade do local, e também, locais com solo exposto, que serve de alerta para possíveis processos erosivos, influenciando negativamente a dinâmica de transporte e deposição de sedimentos. Além disso, é interessante notar a presença de um plantio de frutíferas permanentes em quadra urbana ainda não povoada da cidade de Palmas.

Analisando o curso d'água conforme prevê a Lei Federal $n^{\circ} 12.651 / 2012$, as características do Córrego Brejo Comprido o enquadram na necessidade de preservação de trinta metros partindo da borda da calha do leito regular, o que na maior parte do curso, é de fato cumprido. Entretanto, como já exposto, através da lei complementar municipal $\mathrm{n}^{\circ}$ $155 / 2007$, toda a extensão em área urbana do córrego fica entendida como "Unidade de Conservação Brejo Comprido", com uma faixa preservação de cem metros, o que na prática não é respeitado, conforme demonstrado.

\section{CONSIDERAÇÕES FINAIS}

O presente trabalho caracterizou espacialmente a área entorno do Córrego Brejo Comprido, mas não diagnosticou a intensidade dos impactos encontrados, tendo em vista que 

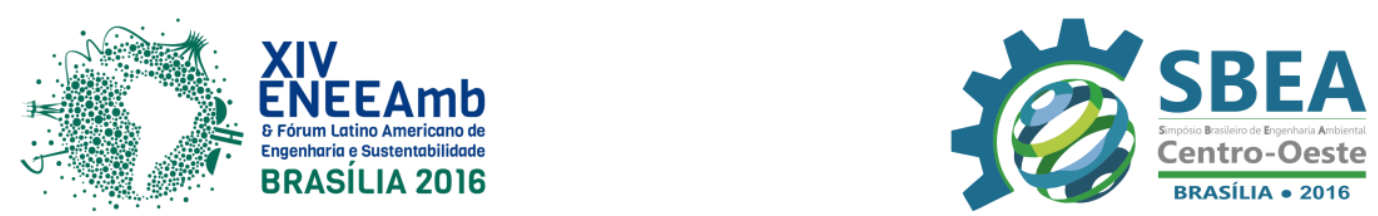

a realização do mesmo necessitaria de uma análise temporal para avaliação do processo de ocupação, sendo isso recomendado para estudos posteriores mais detalhados.

A utilização de imagem de melhor resolução espacial fornecida pelo programa Google Earth Pro, demonstrou ser uma excelente ferramenta no monitoramento ambiental, com seus benefícios expressos na variedade de classes que puderam ser geradas, corroborando para que cada vez mais os estudos ambientais sejam mais detalhados e contribuam para promoção de políticas aplicáveis a realidade.

Contudo, o Córrego Brejo Comprido, como muitos outros, é prova de que nem sempre a determinação de políticas públicas são o suficiente para que de fato uma área com necessidade de preservação reconhecida seja na prática respeitada, mas com a avaliação das áreas de interesse e através do monitoramento das mesmas por meio de tecnologias cada vez mais aprimoradas, tanto a fiscalização, quanto a formulação de políticas de preservação tendem a tornarem-se mais assertivas.

\section{Agradecimentos}

Ao Laboratório de Cartografia e Geoprocessamento da Universidade Federal do Tocantins, câmpus Palmas.

\section{REFERÊNCIAS}

ARRAIS, M. A. Um estudo para a preservação e uso sustentável da área verde urbana do Córrego Brejo Comprido em Palmas - TO. Brasília, 243p, 2009. Dissertação (mestrado) - Universidade de Brasília.

BRASIL, Lei $n^{\circ} 12.651$ de 25 de maio de 2012. Dispõe sobre a proteção da vegetação nativa; altera as Leis $\mathrm{n}$ os 6.938, de 31 de agosto de 1981, 9.393, de 19 de dezembro de 1996, e 11.428, de 22 de dezembro de 2006; revoga as Leis $\mathrm{n}^{\mathrm{os}}$ 4.771, de 15 de setembro de 1965, e 7.754, de 14 de abril de 1989, e a Medida Provisória no 2.166-67, de 24 de agosto de 2001; e dá outras providências. Disponível em:< http://goo.gl/JGUUeu $>$. Acesso em: 27 de abr. 2016.

COELHO, V. H. R. et al. Dinâmica do uso e ocupação do solo em uma bacia hidrográfica. Ver. Bras. Eng. Agrícola e Ambiental. V.18, N.1, P64-72, 2014.

GUARDA, S. D. M. Expansão urbana do entorno do lago do município de Palmas - TO (1990, 1993, 1999, 2002, 2005): acompanhamento por dados de sensoriamento remoto. Palmas, 132p, 2006. Dissertação (Mestrado em Ciência do Ambiente) - Universidade Federal do Tocantins.

IBGE. Instituto Brasileiro de Geografia e Estatística. Manual técnicos da vegetação brasileira. 2ed. Rio de Janeiro: 2013. 

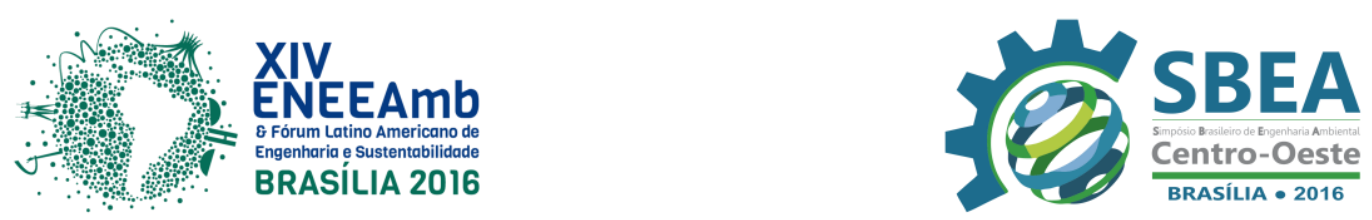

IBGE. Instituto Brasileiro de Geografia e Estatística. Manual técnicos de uso da terra. 3ed. Rio de Janeiro: 2012.

IBGE. Instituto Brasileiro de Geografia e Estatística. Censo Demográfico de 1991: resultados preliminares. Rio de Janeiro: 1992.

PALMAS, Prefeitura Municipal de. Plano Municipal de Saneamento Básico de Palmas TO. Anexo III ao Decreto $\mathrm{n}^{\mathrm{o}}$ 700, de 15 de janeiro de 2014. Vol III: Drenagem Urbana. Palmas. 2014.

PALMAS. Lei Complementar 155, de 28 de dezembro De 2007. Dispõe sobre a política urbana do município de palmas, conforme estabelece a constituição federal/88, em seus arts. 182 e 183, e o estatuto da cidade, lei federal n ${ }^{\circ} 10.257$, de 10 de julho de 2001. Disponível em: < https://goo.gl/x4q3tx $>$ Acesso em: 27 de abr. 2016.

PALMAS. Lei 1.406 de 16 de dezembro de 2005. Institui o plano de uso de ocupação do Parque Cesamar e dá outras providências. Disponível em: 〈 https://goo.gl/eg8spw $>$. Acesso em: 27 de abr. 2016.

SOUZA, R. M. S.; FIGUEROA, F. E. V. Análise de variáveis aplicada à gestão de recursos hídricos - caso de estudo da microbacia do córrego Brejo Comprido, Palmas TO. Rev. Engenharia Ambiental. v.9, n.3, p. 303-319, jul/set, 2012. 